\title{
Teknologi Pengukuran Online Pasang Surut dengan Sensor Ultrasonik dan Berbasis Realtime Web
}

\author{
Khoirol Imam Fatoni, Tunggul Puliwarna, Parluhutan Manurung \\ Program Studi Strategi Operasi Laut Dikreg Seskoal Angkatan ke-57 Sekolah Staf dan Komando Angkatan Laut \\ Jl. Ciledug Raya No.2. Komplek Seskoal, Cipulir, Kebayoran Lama, Jakarta, 12230 \\ Email: khoirolimam_fatoni@tnial.mil.id
}

\begin{abstract}
Abstrak
Pengembangan teknologi sensor ultrasonik yang relatif terjangkau dan berkualitas untuk pemantauan dinamika muka air laut di perairan Indonesia dapat dikatakan masih relatif terbatas di Indonesia. Sementara kebutuhan studi untuk kepentingan riset hidrografi, oseanografi, kegiatan pelayaran, riset datum vertikal, dan pemantauan bencanaseperti banjir dan bencana tsunami, sangat penting dikembangkan. Di era 4.0 saat ini, perkembangan teknologi komunikasi data digital GPRS sudah hampir mencakup seluruh pelosok negeri, ditambah banyaknya komponen elektronik dan sensor yang dapat diintegrasikan sesuai dengan kebutuhan,makalebih mudah menerapkan konsep pengukuran dengan sistem online yang mempunyai kemampuan realtime monitoring terkoneksi dengan jaringan internet. Hasil penelitian menunjukkan diperolehnya teknologi sistem pengukuran realtime yang terdiri atas 5 komponen yang terintegrasi yaitu; 1 ) Sensor pemantau tinggi permukaan air presisi, 2) Data Logger dengan microcontroller yang mengatur sensor, modem GPRS/GSM, power system, memory card, dan GPS Timing, 3) Cloud data server, dan 4) Aplikasi online monitoring. Pengukuran dengan sistem online ini sudah diinstalasi Pushidrosal untuk kepentingan pengukuran pasang surut periode panjang di beberapa lokasi strategis. Seluruh stasiun menghasilkan data sekitar $98 \%$ per tahun. Peralatan pengukuran yang dihasilkan, mudah dioperasikan, mudah dimobilisasi, kandungan material lokal, serta data yang diperoleh mempunyai ketelitian pengamatan $<1 \%$ dengan ketinggian terkontrol GPS serta interval pengukuran hingga 1 menit.
\end{abstract}

Kata kunci: ultrasonik, online, GPRS, pasang surut, real time

\section{Abstract \\ Online Tidal Measurement Technology with Ultrasonic Sensors and Realtime Web Based}

The development of ultrasonic sensor technology that is relatively affordable and of high quality for monitoring sea-level dynamics in Indonesian waters can be said to be still relatively minimal in Indonesia. While the need for studies for research purposes is required to serve various applications such as hydrographic research, oceanography, shipping activities, vertical datum research, and monitoring disasters such as floods and tsunami disasters, are essential to be developed. In the $4.0 \mathrm{era}$, the development of GPRS digital data communication technology has almost covered all corners of the country, plus many electronic components and sensors that can be integrated according to needs, and it is easier to apply the concept of measurement with online systems that have realtime monitoring capabilities connected to the internet network. The results showed the realtime measurement system technology consisting of 5 integrated components namely; 1) Sensor for precision water level monitoring, 2) Data Logger with a microcontroller that controls sensors, GPRS / GSM modem, power system, memory card, and GPS Timing, 3) Cloud data server, and 4) Online monitoring application. Measurement with this online system has been installed by Indonesian Naval Hydrographic and Oceanographic Center for measuring long-term tides in several strategic locations, and all stations produce about $98 \%$ of data per year. Measuring equipment easy to operate, easy to mobilize, local material content, as well as data obtained has observation accuracy $<1 \%$ with GPS controlled altitude and data interval until 1 minute.

Keywords : ultrasonic, online, GPRS, tides, real time

\section{PENDAHULUAN}

Kebutuhan nasional untuk pemantauan pasang surut permanen, real time dan akurasi tinggi diperlukan untuk mendukung kegiatan pemetaan, riset oseanografi, perubahan iklim, tsunami, dan keselamatan pelayaran. (Susmoro.

\footnotetext{
*Corresponding author

DOI:10.14710/buloma.v8i2.25349
}

http://ejournal.undip.ac.id/index.php/buloma

Diterima/Received : 30-08-2019

Disetujui/Accepted : 29-09-2019 
2019) Keberadaan Jaring Pasang Surut nasional yang ada saat ini masih sekitar 160 stasiun, sementara kebutuhan ideal 2000 stasiun meliputi 1340 pelabuhan nasional dan 560 stasiun lokasi startegis untuk memenuhi distribusi ideal pemantauan di sepanjang $82000 \mathrm{~km}$ garis pantai Indonesia (BIG. 2015). Peralatan pengukur pasang surut yang ada, masih memerlukan komunikasi data dari sensor ke server dan membutuhkan waktu tertentu untuk dirilis admin kepada pengguna melalui website. Pengukuran pasang surut dengan sistem online berbasis realtime web merupakan solusi dari teknologi yang mempunyai kemampuan realtime monitoring terkoneksi dengan jaringan internet. (Manurung. 2017). Hasil penelitian menunjukkan teknologi sistem pengukuran realtime yang terdiri atas 5 komponen yang terintegrasi yaitu; 1) Sensor pemantau tinggi permukaan air presisi, 2) Data Logger dengan microcontroller yang mengatur sensor, modem GPRS/GSM, power system, memory card, dan GPS Timing, 3) Cloud data server, dan 4) Aplikasi online monitoring. (Fatoni. 2014).

Pengukuran dengan sistem online ini sudah diinstalasi Pushidrosal untuk kepentingan pengukuran pasang surut periode panjang di beberapa lokasi strategis, serta seluruh stasiun menghasilkan data sekitar 98\% per tahun.(Kamija, 2014). Terdapat 4 keunggulan dalam sistem online pengukuran pasang surut yang dihasilkan dalam penelitian, yaitu Partnership: pengoperasian peralatan dilakukan bersama antara operator alat dengan dengan provider melalui media monitoring real time berbasis web, Reliability: peralatan cukup terjaga beroperasi penuh dan trouble shooting secara cepat melalui monitoring real time, Quality: data sesuai dengan standar internasional seperti yang ditetapkan guide line Intergovermental Oceanographic Comission (IOC) UNESCO yaitu dengan resolusi data milimeter, ketelitian pengamatan $<1 \%$ dan time drift dan height terkontrol GPS dan insitu calibration. (Manurung. 2017). Diharapkan sistem online pengukuran pasang surut Pushidrosal, dapat menambah kemampuan bangsa Indonesia mencakup seluruh wilayah perairan nusantara melengkapi pengukuran permanen yang telah dillaksanakan oleh berbagai kementrian dan lembaga pemerintah. (Kamija, 2014)

\section{MATERI DAN METODE}

Metode Pengukuran pasang surut ini dilengkapi dengan sensor water level tipe ultrasonik, yaitu sensor yang mengukur tinggi permukaan air tanpa kontak langsung dengan air dengan ketelitian milimeter. Metode pengamatan ersifat permanen dan kontinyu sehingga dapat menghasilkan data time series periode panjang dengan kualitas pengukuran homogen. Sistem pengukuran dibuat real time berbasis web yang dapat dipantau baik melalui komputer maupun dengan smartphone sehingga proses pengamatan dapat terpantau baik dimana saja dan kapan saja sepanjang tersedia jaringan internet provider telekomunikasi. Sistem pemantauan menggunakan water level sensor yang dikendalikan oleh microcontroller unit (MCU). Modem GPRS digunakan sebagai modul komunikasi sehingga alat ini bisa terkoneksi dengan sebuah web server atau dipantau melalui SMS. Untuk keperluan timing yang akurat, digunakan modul GPS, sehingga setiap data yang dikirim ke server akan mempunyai time stamp yang akurat. Sebuah mikro SD ditambahkan sebagai penyimpan data apabila koneksi GPRS terputus. Ketika sudah terhubung kembali, data dari memori secara otomatis akan dikirim ke server, atau bisa juga di-download dengan PC/Laptop melalui kabel USB.

Alat ukur pasang surut online yang menggunakan sensor ultrasonic adalah Live Uninterrupted Water Sensor (LUWES). Prinsip kerja alat ini menggunakan sistem radar, dengan mengukur tinggi muka air laut tanpa menyentuh permukaan air dan mampu mengirimkan data rekaman melalui jaringan GPRS ke admin pengendali. Pengoperasian peralatan secara otomatis, pemantauan data bisa dilaksanakan secara mobile, alat bersifat portable memudahkan dalam instalasi, mudah dikalibrasi, serta data bersifat real time. (Manurung. 2017).

Diagram sistem perangkat keras dari logger pasang surut tertera seperti pada Gambar 1. Menggunakan mikrontroller yang mempunyai konfigurasi input dan output sesuai dengan keperluan. Memiliki frekuensi internal dan flash sebesar $512 \mathrm{~KB}$ sehingga lebih optimal. Jumlah port UART sebanyak 4 buah digunakan untuk sensor ultrasonik, modul GPS, modul USB dan modem GPRS. Terdapat 2 port ADC digunakan untuk sensor tegangan dan arus, 1 port digunakan untuk EEPROM dan 1 port SPI digunakan SD card.

Fungsi dari tiap input dan output pada Gambar 1: Sensor ultrasonik digunakan untuk mengukur jarak dengan permukaan air, memiliki frekuensi sampling sebesar 100Hz. Disamping itu sensor tidak kontak dengan air secara langsung, sehingga sensor less maintenance dan akan lebih awet. GPS modul digunakan sebagai referensi waktu dan lokasi dari logger pasang surut. 
Penggunaan GPS dilakukan untuk mendapatkan data yang lebih presisi dan real time. USB port didapatkan dari UART TTL to USB konverter, digunakan untuk debugging firmware, seting logger dan update firmware. Modem GPRS digunakan untuk mengirim data ASCII ke cloud server dalam interval tertentu sesuai seting, dan juga untuk command seting melalui SMS. SD card digunakan untuk menyimpan data pasut dalam interval tertentu sesuai seting. EEPROM digunakan untuk menyimpan data seting. Voltage dan current sensor digunakan untuk monitoring tegangan baterai dan konsumsi arus.

Short flowchart dari firmware logger pasang surut tertera seperti pada Gambar 2. Untuk program compiler menggunakan AC6 eclipse yang umum dipakai dan firmware flasher menggunakan ST-link. Start sistem pada firmware dimulain dengan inisialisasi port input output, kemudian dilanjutkan dengan pembacaan seluruh sensor. Sebelum melakukan pengiriman ke cloud server, controller berkomunikasi dengan modem GPRS

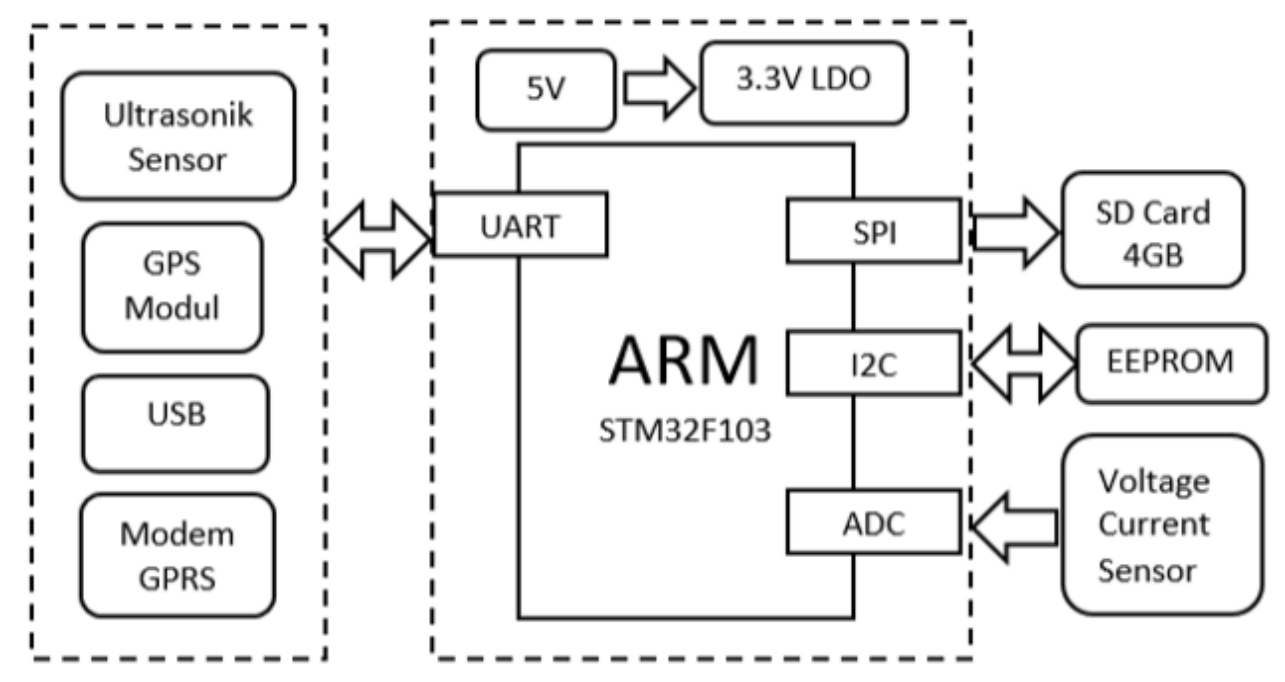

Gambar 1. Diagram Sistem Perangkat Keras

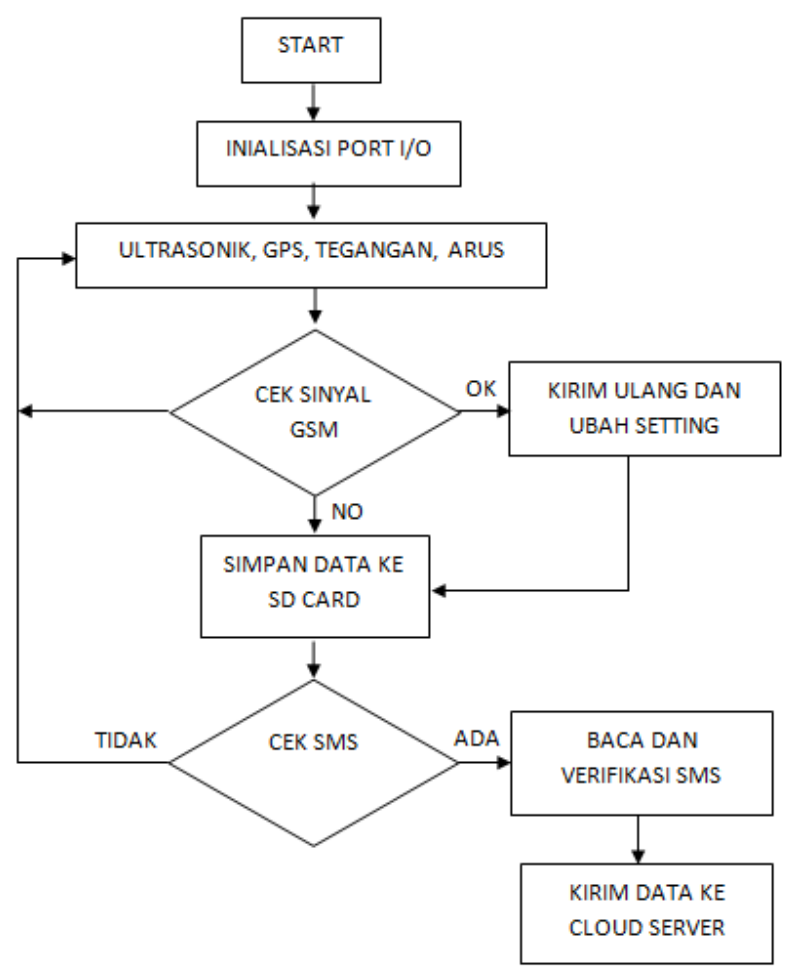

Gambar 2. Alur kerja Firmware 
untuk memastikan bahwa sinyal GSM daerah tersebut dalam keadaan baik. Apabila sinyal dalam keadaan tidak baik maka data tidak dikirim dan disimpan ke SD card. Kemudian data yang sama akan dikirim ulang hingga ketika sinyal terdeteksi dengan baik tanpa menghapus data-data selanjutnya. Penggunaan SD card digunakan sebagai second backup data apabila diinginkan data secara langsung, seperti kegiatan survei dan maintenance, juga untuk menyimpan konfigurasi logger.

Pengecekan dan verifikasi data SMS dilakukan apabila terdapat pesan yang masuk. User yang meminta informasi stasiun pasang surut pada saat itu dan juga perubahan seting yang diperlukan. Apabila verifikasi SMS benar maka controller akan mengirim balasan SMS dengan format tertertentu.

Water Level sensor pasang surut memiliki diagram yang tertera pada Gambar 3. Untuk power utama menggunakan battery $12 \mathrm{~V}$ dan solar panel untuk re-charging sehingga alat ini akan lebih ramah lingkungan. Logger akan mengirimkan data ke cloud server via IP dalam interval tertentu yang telah di seting, selama terdapat sinyal GPRS. Dari cloud server, user bisa menggunakan web online atau aplikasi android untuk mengamati hasil data pasang surut.

Alat dipasang dengan desain fisik yang lebih sederhana. Desain dudukan alat ditujukan untuk peruntukan outdoor, sehingga diperlukan bahan yang tahan panas dan anti karat. Alat juga dirancang untuk mudah terpasang yang biasa disebut dengan system plug and play. Sehingga hanya membutuhkan durasi waktu 2 jam untuk instalasi. Faktor utama dari desain alat adalah tidak mengambil ruang terlalu besar di pelabuhan dan dapat diposisikan pada titik pembacaan yang tidak mengganggu pelabuhan (Gambar 4).

\section{HASIL DAN PEMBAHASAN}

Hasil pengukuran online pasang surut menggunakan sensor ultrasonik Luwes oleh Pushidrosal selama 365 hari pada Tahun 2016, menunjukkan bahwa data yang terkirim ke webserver berjalan dengan baik dengan interval 10 detik. Data diunduh setiap hari di Posko Pasut Telemetri Pushidrosal. Data yang diperoleh mempunyai ketelitian pengamatan $<1 \%$ dengan ketinggian terkontrol GPS serta interval pengukuran hingga 1 menit. Format data yang diterima sudah dalam bentuk txt, sehingga mempermudah proses pengolahan berikutnya. Data ukur pasut sistem online dapat diakses melalui website www.pushdrosal.go.id (Gambar 5) dan dapat disesuaikan dengan kebutuhan kerapatan data yakni 1 menit, 3 menit, 5 menit, 15 menit, dan 1 jam.

Hasil Pengolahan data pasut online sekitar Kalimantan Utara, menunjukkan bahwa konstanta pasut yang dihasilkan sebanyak 59 konstanta berbagai variasi air yakni variasi harian, bulanan, variasi 3 bulanan, variasi 6 bulanan, variasi 1 tahun, dan Nilai $\mathrm{Z}_{0}$ LAT sebesar $168,65 \mathrm{~cm}$ di bawah MSL. Nilai Z0 yang diperoleh tersebut mempunyai selisih $1.35 \mathrm{~cm}$ dengan $\mathrm{Z0}$ yang ditetapkan Pushidrosal sebesar $170 \mathrm{~cm}$ dibawah MSL.

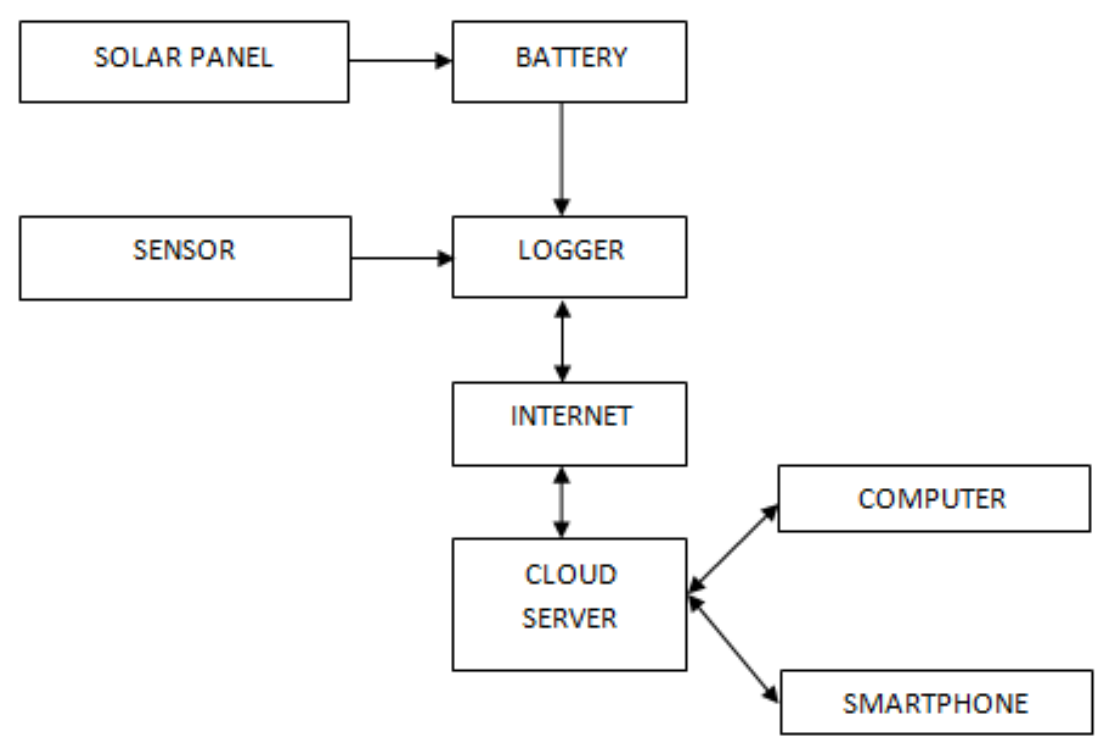

Gambar 3. Diagram Sensor Waterlevel 
Teknologi pemantauan pasang surut secara real time mempunyai peran yang sangat penting untuk menunjang keselamatan pelayaran, navigasi, dan pengelolaan pelabuhan. Namun hingga saat ini belum tersedia sistem nasional yang terintegrasi untuk melayani aktivitas navigasi laut nasional. Pelayaran dengan sistem navigasi menggunakan peta pelayaran digital yang akurat tidak relevan lagi bila menggunakan data pasang surut hasil prediksi karena perbedaan prediksi dengan data real time pasang surut dapat berbeda sekitar 30-50 cm (Pugh, 1987).
Kebutuhan pemantauan muka air juga dibutuhkan pada sungai dalam hal ketersediaan data yang dapat digunakan Pemerintah Daerah dalam berbagai bidang seperti pengelolaan tambak ikan, navigasi, saluran irigasi untuk sawah maupun lahan sekitar, serta pemantauan kualitas air yang akan dimanfaatkan sebagai sumber air untuk keperluan sehari-hari masyarakat. (Rawi, 2010). Menindaklanjuti kebutuhan akan pemantauan sungai tersebut maka diperlukan sistem yang mampu mengamati secara real time dan kontinu terhadap tinggi muka air sungai dan pasang surut

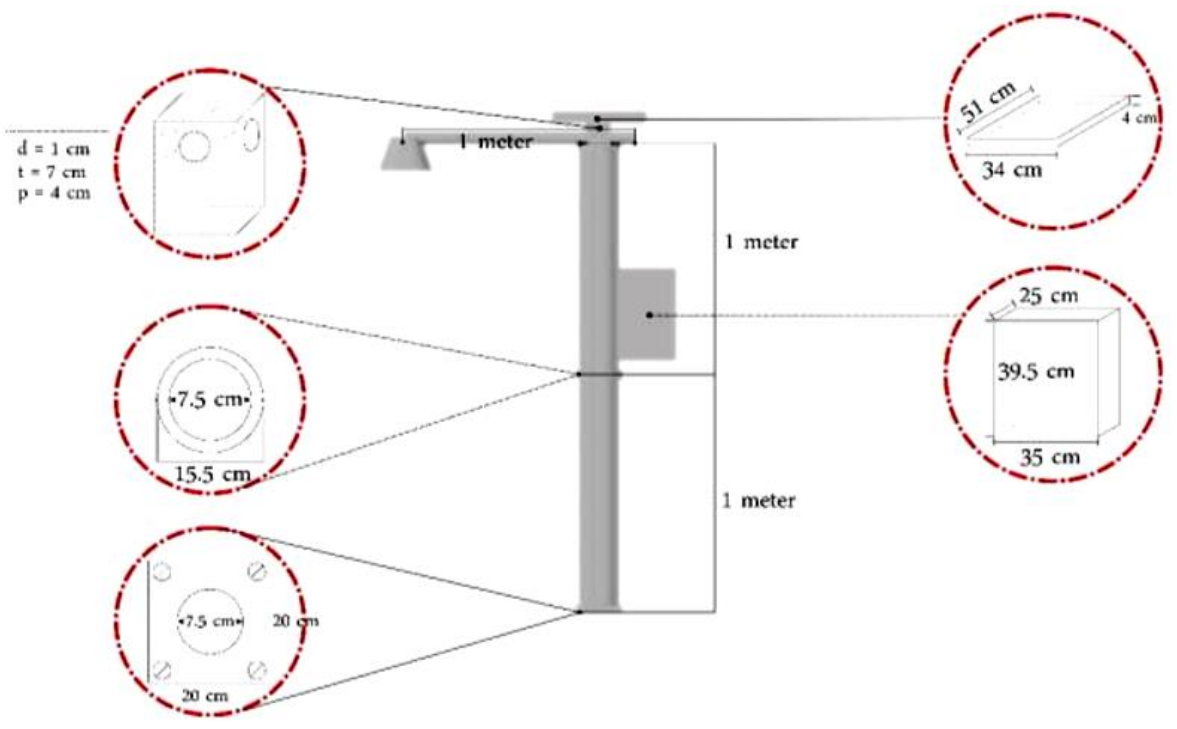

Gambar 4. Dudukan Alat dan Sensor

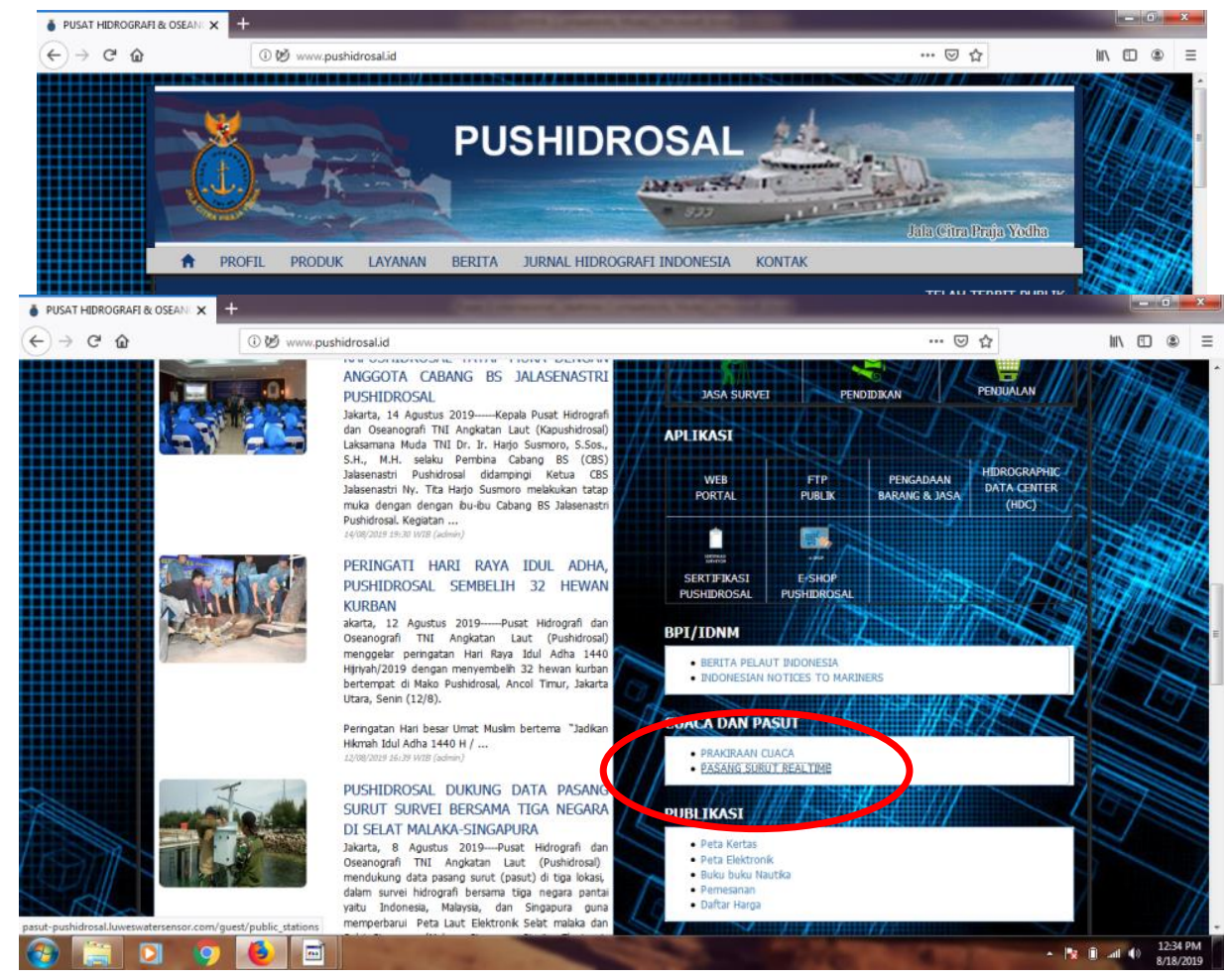

Gambar 5. Tampilan di Website Pushidrosal 
melalui portal yang dapat diakses oleh pihak-pihak yang terkait. Metoda pengamatan diusulkan bersifat permanen dan kontinu sehingga dapat menghasilkan data time series periode panjang dengan kualitas pengamatan homogen. Sistem pemantauannya dibuat real time berbasis web yang dapat dipantau baik melalui office computer maupun dengan smart phone sehingga proses pengamatan dapat terpantau. Sistem pemantauan online ini telah terpasang di 49 pelabuhan toll laut oleh Kementrian Perhubungan, 7 stasiun di perbatasan oleh Pushidrosal, 2 stasiun di Pelabuhan Perikanan, 2 stasiun untuk property di Jakarta, dan 1 stasiun di Danau Toba. Terdapat juga beberapa stasiun yang digunakan untuk operasi pertambangan yang diadakan oleh PT Timah. Seluruh stasiun permanen ini sukses menghasilkan keberadaan data sekitar $98 \%$ per tahun.

Water level sensor telah terpasang pada 9 lokasi dengan sistem yang mampu mengirim data ke web secara real - time. Setiap stasiun di lapangan menggunakan interval akusisi data setiap 30 detik yang akan dikirimkan ke server cloud dan via GPRS dan terkoneksi di Server I-Magic Pushidrosal. Data tersebut dapat dipantau melalui website www.pushidrosal.id untuk pengguna umum sehingga dapat diakses melalui berbagai platform seperti handphone, laptop, komputer maupun diakses oleh server lain.

Pengguna juga dapat menggunakan SMS untuk menerima data dari server terkait posisi pelabuhan yang diinginkan beserta tinggi muka air dan waktu akusisi data terakhir. Data dapat digunakan untuk pemantauan secara berkelanjutan navigasi kapal serta dapat digunakan untuk diintegrasikan sistem lain seperti ECDIS (Electronic Chart Display) dan Vessel Traffic Service System yang telah tersedia di beberapa pelabuhan besar di Indonesia

\section{KESIMPULAN}

Seluruh stasiun permanen ini sukses menghasilkan keberadaan data sekitar $98 \%$ per tahun. Hasil data dapat diamati melalui web online dan aplikasi android yang telah disediakan oleh pihak-pihak yang membutuhkan informasi baik pemerintah, akademisi maupun masyarakat umum. Pengembangan lebih lanjut masih diperlukan untuk membuat display monitoring yang lebih user friendly dan integrasi data logger dengan modem data radio dan satelit di lokasi coverage GPRS yang belum tersedia. Data yang diperoleh mempunyai ketelitian pengamatan $<1 \%$ dengan ketinggian terkontrol GPS serta interval pengukuran hingga 1 menit. Format data yang diterima sudah dalam bentuk txt, sehingga mempermudah proses pengolahan berikutnya. Data ukur pasut sistem online dapat diakses melalui website www.pushdrosal.go.id dan dapat disesuaikan dengan kebutuhan kerapatan data yakni 1 menit, 3 menit, 5 menit, 15 menit, dan 1 jam.

\section{DAFTAR PUSTAKA}

Badan Informasi Geospasial., 2015. Paradigma Geomaritim. Prosiding Badan Informasi Geospasial. Bogor

Fatoni, K.I., 2014, Kegiatan Pengukuran Pasang Surut Air Laut dengan Sistem Telemetri. Majalah Cakrawala, Edisi 3-2015 .

International Hydrographic Office., 2011. Global Spatial Data Infrastructure (GSDI) Cookbook, Spatial Data Infrastructures "The Marine Dimension", Guidance for Hydrographic Offices. IHO Publication C-17 - Edition 1.1.0.

Kamija, 2014. Pushidrosal Melaksanakan Pengukuran Pasang Surut di Choke Point Perairan Indonesia. Pushidros TNI AL. Majalah Cakrawala, Edisi 4.

Manurung, P., 2017. Inovasi Real Time Water Level Sensor Untuk Pemantauan Hidrologi Dan Oseanografi Serta Deteksi Bencana Banjir Dan Tsunami. Seminar Pusat Litbang Sumber Daya Air Badan Penelitian Dan Pengembangan Kementrian Pekerjaan Umum Dan Perumahan Rakyat. Jakarta

Pugh, D.T., 1987. Tides, surges and mean sealevel: a handbook for engineers and scientists. Wiley, Chichester, 472pp.

Rawi, S., 2010. Pasang Surut, Pengantar Pasang Surut. Penerbit STTAL.

Susmoro, H. 2019. Strategi Pertahanan Maritim Kontemporer. Kuliah Umum untuk Pasis Dikreg 57 Seskoal. 